\title{
Private well installation trends and correlation of borehole stratigraphy with groundwater arsenic contamination in Kandal Province, Cambodia
}

KELSEY ROMERO AND MICHAEL SCHAEFER

New Mexico Tech

Presenting Author: kelsey.madison.romero@gmail.com

Arsenic (As) exposure via contaminated drinking water continues to threaten the health of millions of people worldwide. Despite recent advances in the prediction of As contaminated groundwater ${ }^{1}$ and dissemination of the risks of As to human health, wells continue to be installed in regions with known groundwater contamination. In addition, manganese (Mn) exposure through drinking water poses health risks, and often occurs distinct from As contamination in groundwater. ${ }^{2}$ We collected basic stratigraphic data (texture and color) at $3 \mathrm{~m}$ depth resolution from $>500$ wells installed in and near a known Asand Mn-affected region in Kandal Province, Cambodia, between 2013-2015. Sediment stratigraphy combined with an existing database of groundwater quality ${ }^{2}$ shows trends in well installation (e.g. number of wells installed per year) in areas with known groundwater contamination following government and non-government (NGO)privately organized As education and awareness campaigns, providing insight on the effect of As awareness programs on new well installations in a known Asaffected region. Further, by combining sediment stratigraphy with groundwater quality data, we also testshow spatial correlation between sediment color, aqueous redox indicators (e.g. $\mathrm{Fe}(\mathrm{II})$ and $\mathrm{Eh}$ ), and groundwater quality (As, Mn). Our hypothesis was that red, orange, and yellow sediments at the screened interval would be proximal to groundwater low in As and with high (oxidizing) Eh. Conversely, wells screened in blue, black or grey sands would be proximal to higher As concentrations and lower Eh. By incorporating results of intensely studied transects and groundwater flow models in the area $^{3,4}$ with an expanded description of subsurface stratigraphy we aim to test additional sedimentary controls on the distribution of high As groundwater in Cambodia.

[1] Podgorski, J. \& Berg, M. Science 368, 845-850 (2020).

[2] Ying, S. C., Schaefer, M. V., Cock-Esteb, A., Li, J. \& Fendorf, S. Environmental Science and Technology 51, 89268932 (2017).

[3] Benner, S. G. et al. Applied Geochemistry 23, 3072-3087 (2008).

[4] Richards, L. A. et al. Journal of Hydrology 557, 321-334 (2018). 